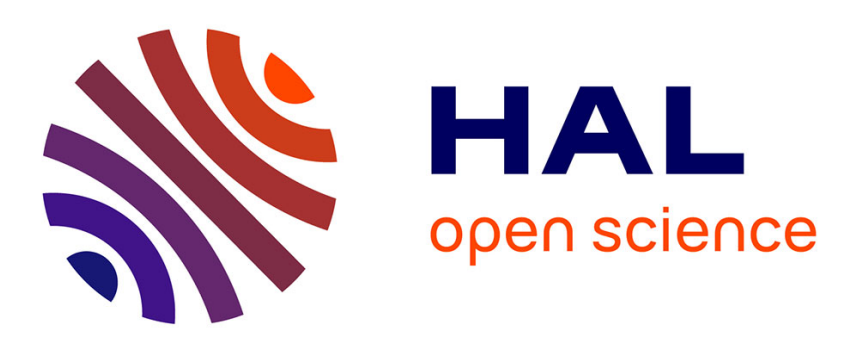

\title{
Numerical Simulation of Collision Process of High Speed Debris against Thin Plate
}

\author{
T. Shirakashi, T. Obikawa
}

\section{To cite this version:}

T. Shirakashi, T. Obikawa. Numerical Simulation of Collision Process of High Speed Debris against Thin Plate. Journal de Physique IV Proceedings, 1997, 07 (C3), pp.C3-1027-C3-1032. 10.1051/jp4:19973173 . jpa-00255465

\section{HAL Id: jpa-00255465 https://hal.science/jpa-00255465}

Submitted on 1 Jan 1997

HAL is a multi-disciplinary open access archive for the deposit and dissemination of scientific research documents, whether they are published or not. The documents may come from teaching and research institutions in France or abroad, or from public or private research centers.
L'archive ouverte pluridisciplinaire HAL, est destinée au dépôt et à la diffusion de documents scientifiques de niveau recherche, publiés ou non, émanant des établissements d'enseignement et de recherche français ou étrangers, des laboratoires publics ou privés. 


\title{
Numerical Simulation of Collision Process of High Speed Debris against Thin Plate
}

\author{
T. Shirakashi and T. Obikawa \\ Department of Mechano-Aerospace Engineering, Tokyo Institute of Technology, 2-12-1 Okayama, \\ Meguro-ku, Tokyo 152, Japan
}

\begin{abstract}
A collision process of a high speed debris with a spherical or cylindrical shape against a thin plate, which were parts of a satellite and made of an aluminum or its alloy, was numerically simulated based on a thermo-elasto-plastic FEM. In the simulation the effects of strain, strain rate and temperature including the heating effect resulting to melt away of materials were simultaneously considered. The collision of the high speed debrises, with larger than $2000 \mathrm{~m} / \mathrm{sec}$, causes melting away of both a debris and a plate. The spalling fracture in bottom side of a plate can be only seen in a collision of relatively slow speed debris.

RésuméCet article se concerne avec les calculs numériques utilisant thermo-élasto-plastique FEM de la collision entre des gravats sphériques ou cylindriques à grande vitesse el une planche construite d'aluminium ou d'une de ces alliages et qui représente une partie d'un satellite. Dans les calculs, les effects du strain, strain-rate, et température, aussi bien que le chauffage qui fait fondre les matériaux, ont été considerés. On decouvre que les collisions avec des gravats d'une vitesse plus*que $2000 \mathrm{~m} / \mathrm{sec}$ occasionent le fondrage aussi bien des gravats que de la planche. Par contre, le fracture spalling à la cote derrière de la planche n'est evident qu'avec des collisions des gravats à vitesse relativement base.
\end{abstract}

\section{Introduction}

In the space around the Earth many satellites with variable functions are working. And many parts and remains of wrecked satellites or rockets are also being near the orbit of the satellites as the high speed debris.

The collision of the debris against the satellite may cause serious problems ${ }^{1) 2}$. In order to avoid the problems, the satellite is covered by the shield or bumper plate. As known well, since the large debrises are already detected and their maps in the orbits are prepared, it is possible to avoid the collision with them. However, the small ones less than $5 \mathrm{~mm}$ diameter are very difficult to be detected and to avoid the collision. For safe and available work of satellite, the suitable defense system for the damage must be designed. As the debris is made of the same material of the satellite's component or element, the collision mechanism should be analyzed under the situation in which the about $5 \mathrm{~mm}$ diameter spherical debris or cylindorical one of Aluminum/Aluminum alloy collide against the thin plate or the bumper of satellite of the same material. Since both of the plate and the debris are made from ductile material, at the collision they will deform and also melt away. The collision process should be analyzed based on stress/strain wave propagation combined with plastic deformation and melt away.

In the paper the materials with the Mises type flow characteristics are assumed and their flow stress characteristics with the function of strain, strain rate and temperature are measured by the impact testing machine. The deformation process, strain/stress wave propagation, temperature and their changes with time at the collision are numerically analyzed through thermo-elasto-plastic FEM. And the finite elements exceed the melting temperature are eliminated from the FEM model.

\section{FEM Model and Formulation}

Since a collision process is an dynamic process with large deformation and temperature rise, an analysis should include an equation of motion, and of unstcady heat transfer.

The equation of motion may be expressed as following matrix equation at a given time tn. 


$$
M \ddot{d} n+C \dot{d} n+p_{n}=f_{n}
$$

where M, C, Pn are mass, damping, internal resistance vector matrixes respectively. $\mathrm{dn}$, dn are acceleration and velocity vector matrixes for each nodal point respectively. The flow stress characteristics include in an internal resistance vector. Equation 1) may be analyzed by an explicit time integral. A timc step for integration $\Delta t$ was determined by the following equation.

$$
\Delta t \leq \frac{2}{w_{\max }} \cong \mu L\left(\frac{\rho(1+v)(1-2 v)}{E(1-v)}\right)^{1 / 2}
$$

where $\varpi_{m a x}$ is the maximum circular frequency of finite element in the model. $E, \rho, \mu$ are Young's Modulus, density and Poisson ratio respectively. $\mathrm{L}$ is the minimum length between nodal points.

A temperature distribution may be analyzed by an unsteady heat transfer equation,

$$
K\{\Phi\}+[C]\left(\frac{\partial \Phi}{\partial t}\right)=\{F\}
$$

where $\Phi, \mathrm{K}, \mathrm{C}, \mathrm{F}$ are nodal temperature, heat conductivity, heat capacity and heat flux matrixes respectively.

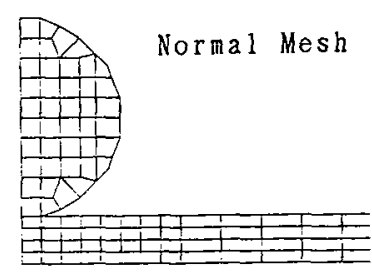

Fig.1 FEM model

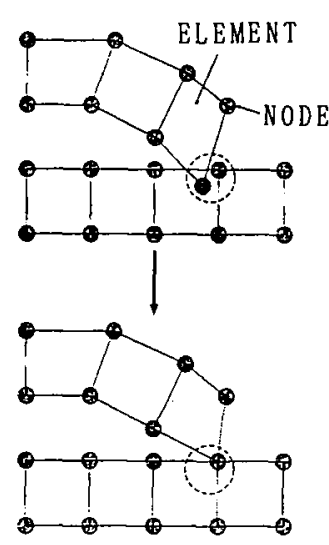

Fig.2 Adhesion and remeshing of FEM nodes

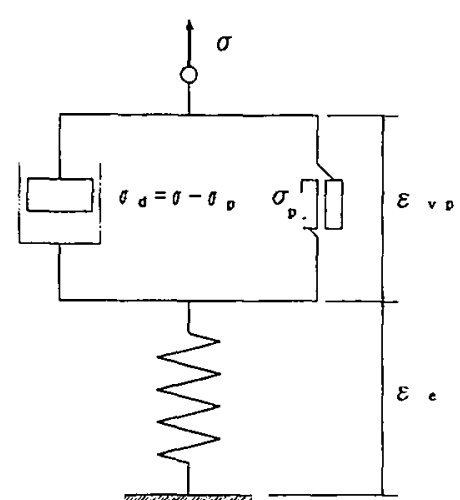

Fig.3 Visco-elasto-plastic model

Fig. 1 shows FEM model for calculation, in which a $5 \phi \mathrm{mm}$ spherical debris impacts a $1.2 \mathrm{~mm}$ thick plate.

In the analysis an isoparametric element with 4 nodes were used, and in the contact area between a debris and a plate the neigbor nodes in both elements of the debris and plate were combined and remeshed to one element as shown in Fig.2. This means ignoring of slip and heat generation caused by friction between them.

The elements which exceed melting temperature were eliminated from the FEM model.

An unconstrained boundry for stress and strain was assumed, because the phenomena to be analyzed was restricted with in very short duration. And an adiabatic boundary for thermal diffusion was also used.

In order to avoid the difficulty for calculation caused by element size, the elasto-visco-plastic constitutive equation 4) was used based on the model shown in Fig. $3^{3)}$. 


$$
\dot{\varepsilon}_{n}=\left[\dot{\varepsilon}_{e}\right]_{n}+\left[\dot{\varepsilon}_{v p}\right]_{n}=[D]^{-1} \dot{\sigma}_{n}+\gamma\left\{\Phi_{n}(F)\right\} \frac{\partial F}{\partial \sigma_{n}}
$$

where $\mathrm{D}, \gamma, \mathrm{F}$ are elastic matrix, visco-parameter and yield function respectively. $\varepsilon \mathrm{n}, \varepsilon e, \varepsilon \vee p$ are also total, elastic and visco-plastic strain rate respectively. And $\Phi n(F)=0$ when the elemnt is not yielded, $\Phi n(F)=1$ when yielded.

The plastic flow stress characteristics shown in equation 5), obtained by the impact testing machine, was also used ${ }^{4}$.

$$
\sigma_{p}=10.9 \varepsilon^{0.3}\left(\frac{\dot{\varepsilon}}{1000}\right)^{0.076} \exp \left(\frac{153}{\theta}\right)
$$

The physical properties of the both materials are shown in table 1).

\begin{tabular}{|c|c|c|}
\hline & A l uminum & $6061-T 6 \mathrm{Alum}$ inum \\
\hline Young modulus & $70.03 \times 10^{\circ}$ & $68.965 \times 10^{\circ}$ \\
\hline Poison ratio & 0.345 & 0.333 \\
\hline$\rho\left(\mathrm{kg} / \mathrm{m}^{3}\right)$ & $2.69 \times 10^{3}$ & $2.71 \times 10^{3}$ \\
\hline yield stress $\sigma_{y}\left(\mathrm{~N} / \mathrm{m}^{2}\right)$ & $150.0 \times 10^{\circ}$ & $300.0 \times 10^{\circ}$ \\
\hline melting point & 660.4 & 700.0 \\
\hline thermal conductivity & $233.0\left(300^{\circ} \mathrm{C}\right)$ & $233.0\left(300^{\circ} \mathrm{C}\right)$ \\
\hline specific heat $C_{p}\left(J / k_{g K}\right)$ & $1030\left(300^{\circ} \mathrm{C}\right)$ & $1030\left(300^{\circ} \mathrm{C}\right)$ \\
\hline
\end{tabular}

Table1)

\section{A collision of an Aluminum Spherical Debris against an Aluminum Alloy Plate}

A spherical aluminum debris, $5 \mathrm{~mm}$ diameter, impacted against an aluminum plate, $1.2 \mathrm{~mm}$ thickness, at $3000 \mathrm{~m} / \mathrm{sec}$.
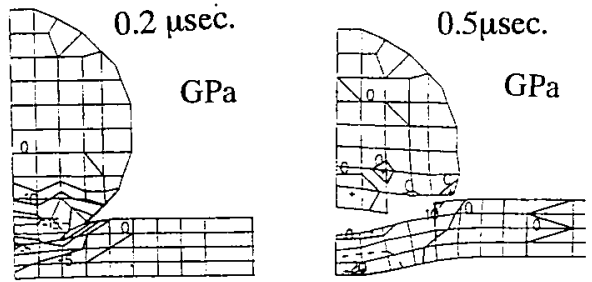

$1.8 \mu \mathrm{sec}$.

$\mathrm{GPa}$

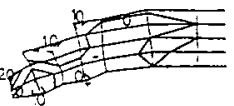

$2.0 \mu \mathrm{sec}$.

$\mathrm{GPa}$

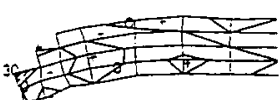

Fig.4 Propagation of principal stress debris speed: $3000 \mathrm{~m} / \mathrm{sec}$, debris: $5 \mathrm{~mm} \phi$ sphere, plate thickness: $1.2 \mathrm{~mm}$

Fig. 4 shows the propagation of principal stress after the impact. The principal stress generated at the center of contact, propagated and expanded in both the debris and the plate. However the maximum stress can be seen in a rim of the contact zone. The high strain rate easily caused high temperature which exceeded the melting one of both an aluminum and its alloy. Therefore after only $0.5 \mu \mathrm{sec}$, when the elastic shock wave generated by impact propagated in the half length of the spherical debris diameter, a quarter part of the debris and the plate melted away. At the instant the tensile principal stress can be seen in the bottom of the plate. When the tensile stress exceeds fracture stress of the plate, the spallation 
fracture may be expected in the bottom.

The melted away parts in both the debris and plate expanded with time and finally an about $5 \mathrm{~mm}$ diameter hole, which is same as the debris size, can be seen in the plate and also the debris perfectly melted away.
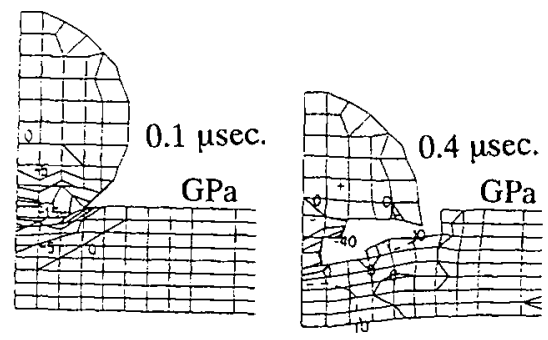

$\left[\begin{array}{l}\text { debris speed: } 3000 \mathrm{~m} / \mathrm{sec}, \\ \text { size: } 2.5 \mathrm{~mm} \phi, \text { plate thickness: } 1.2 \mathrm{~mm}\end{array}\right]$

0.8 usec.

$1.1 \mu \mathrm{sec}$.

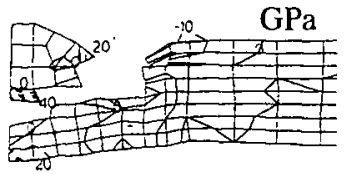

$\mathrm{GPa}$

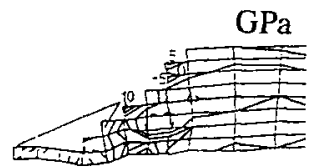

Fig.5 Effect of debris size on collision process

Fig.5 shows the collision process for the smaller debris, $2.5 \mathrm{~mm}$ diameter. In the first step of the process, the same feature can be seen for that of the larger debris, $5 \mathrm{~mm}$ diameter, but at the finally a penetrated hole was not generated and the about $4 \mathrm{~mm}$ diameter crater caused by melted away part in the plate, was generated, which is larger than the debris diameter, $2.5 \mathrm{~mm}$.

\section{Effect of Debris Speed and Debris Geometry on Collision Process}

The effects of debris speed and its geometry on the collision phenomenon were discussed.
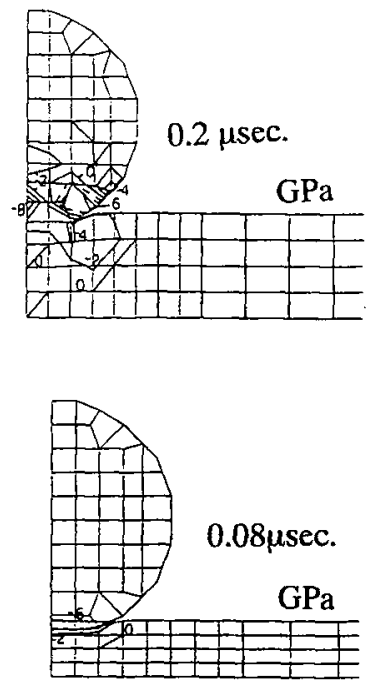

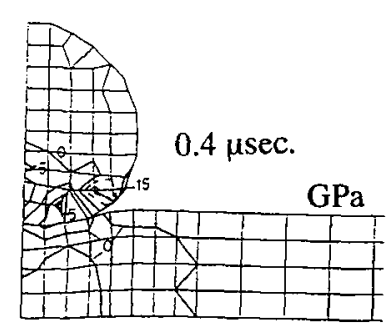

a) $1000 \mathrm{~m} / \mathrm{sec}$

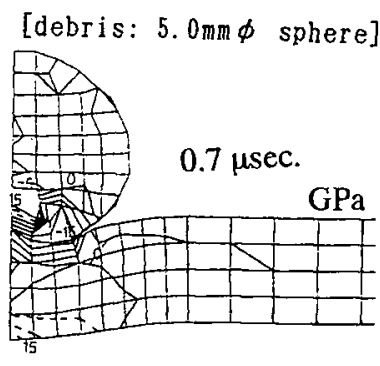

1.6 usec.

$0.8 \mu$ sec.

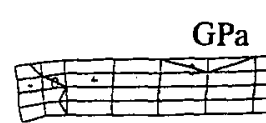

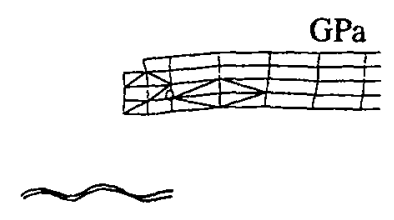

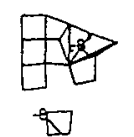

b) $8000 \mathrm{~m} / \mathrm{sec}$

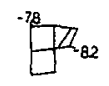

Fig.6 Effect of debris speed on collision process 
Fig.6 shows the changes of principal stress for each debris speed with time. When the speed is $1000 \mathrm{~m} / \mathrm{sec}$, any melted part can not be seen Fig. 6 a), but the speed exceeds $3000 \mathrm{~m} / \mathrm{sec}$, the melted parts were generated in both the debris and the plate Fig.b), Fig.4. The collision by the debris with over $3000 \mathrm{~m} / \mathrm{sec}$ causes to make the hole with the about same diameter of the debris, and at the same time the debrises melted away perfectly. the plate.

And the melting in both the debris and the plate continue after the debris had penetrated through
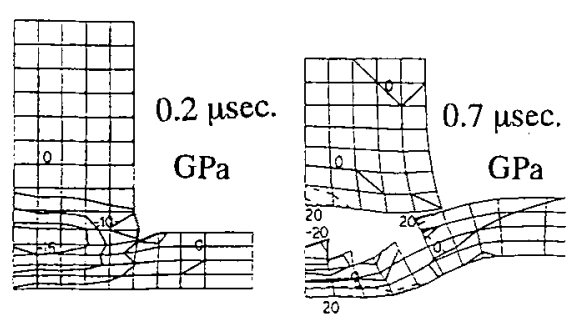

debris speed: $3000 \mathrm{~m} / \mathrm{sec}$

debris geometry: $5 \phi \mathrm{mm} \times 5 \mathrm{~mm}$ length cylinder

Fig.7 Effect of debris geometry

Fig. 7 shows the collision process by a right-circular cylinder debris, whose length is equal to its diameter. At the moment of contact the uniaxial like stress wave was generated from the contact surface.

In this case the maximum principal stress can be seen the rim part of the contact circle, and the stress caused the higher temperature than the inside. The first melted away was seen just inside of the rim part and expanded to inside and also to the out side of plate.

The generated hole size in the plate was larger than that of the debris, about 1.3 times of the debris diameter.

\section{Effect of Thickness of Plate on Perforation}
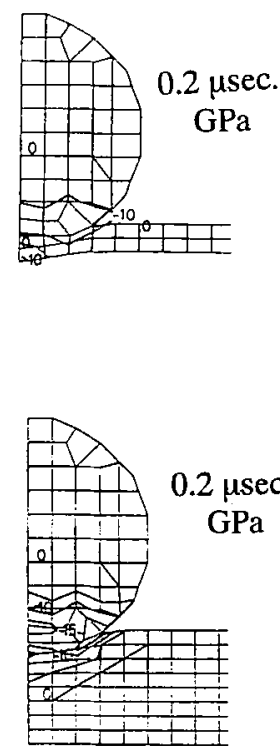

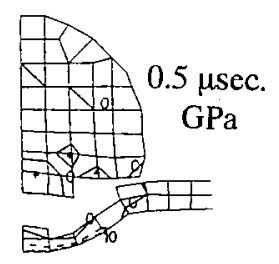

a) plate thickness $0.6 \mathrm{~mm}$

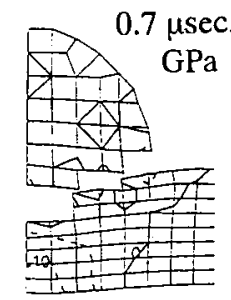

$2.0 \mu \mathrm{sec}$.

$\mathrm{GPa}$

b) plate thickness $2.5 \mathrm{~mm}$

Fig. 8 Effect of plate thickness

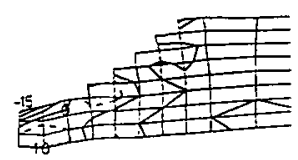

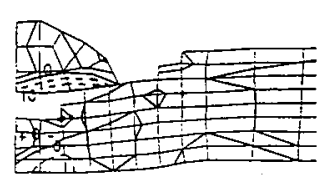

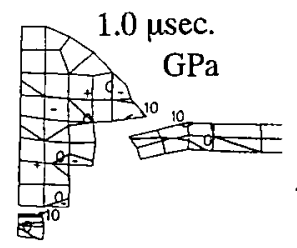

at

3.0 usec.

GPa
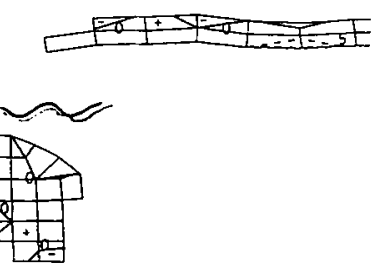
It is very important to protect the perforation of outer plate of satellite by a debris. To increase thickness, strength and melting temperature of the plate is very effective. In order to decrease the weight of satellite, the thickness and specific weight of material to be used is selected as possible as thin and small one. Therefore the most of satellite is generally constructed by an aluminum or its alloy, and the total thickness of plate to be used is also limited. Under the proposed condition it is very important to determine the most adaptive plate construction and its arrangement.

Fig. 8 shows the effect of plate thickness on the collision process. A single thin plate was easily perforated by the debris and after that the debris with high speed, which was melting continuously, was yet remained shown in Fig. 8 a). When the thickness is increased shown in fig. 8 b), the debris did melt away perfectly before the perforation in the plate, and no hole did not generate but the crater was remained.

As seen in Fig. 8 a) the debris, which perforated the plate, was continuously melting with high speed, this means that size of the debris will decrease with time. And the smaller size of debris will give the smaller damage on the plate.

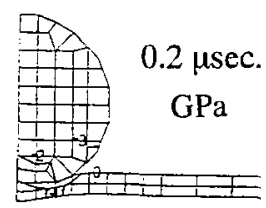

\section{$2.4 \mu \mathrm{sec}$. \\ $\mathrm{GPa}$}

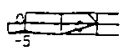
$\left[\begin{array}{l}\text { debris speed: } 3000 \mathrm{~m} / \mathrm{sec}, 5.0 \mathrm{~mm} \phi \text { sphere } \\ \text { plate thickness: } 0.6 \mathrm{~mm}\end{array}\right.$

$2.9 \mu \mathrm{sec}$.

$\mathrm{GPa}$

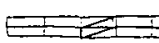

$3.2 \mu \mathrm{sec}$.

$\mathrm{GPa}$
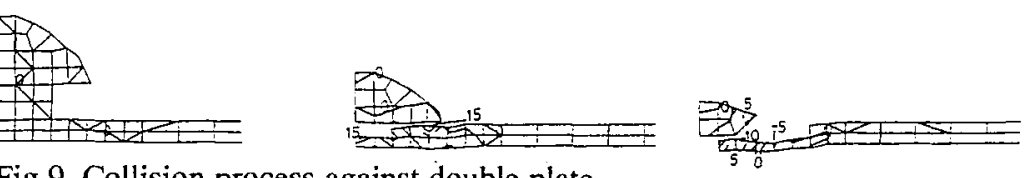

Fig.9 Collision process against double plate

Fig.9 shows the perforation process, when two plates were arranged with some distance. The first plate was easily perforated, however the first collision decreased the debris size about one half of the original one. therefore the second collision did give the smaller damage in the plate. effective.

In order to decrease the damage the multi-layer structure of the plate with some distance is very

\section{Concluding Remarks}

A collision process of a high speed debris against a plate was simulated based on the equation of motion and of heat transfer through a visco-elasto-plastic FEM. In th simulation the constitutive equation and melting phenomenon of both the debris and the plate materials were included.

In the collision by a high speed debris over $3000 \mathrm{~m} / \mathrm{sec}$, the perforation will be mainly caused by melt away of both the debris and the plate proceeding mechanical fracture.

The perforation of plate without melt away caused by the mechanical fracture can be only seen in the collision of low speed debris, less than $2000 \mathrm{~m} / \mathrm{sec}$ for an aluminum material.

In order to avoid the perforation of plate by the collision of high speed debris, the multi-layers system is more beneficial than the thicker single plate one.

\section{Reference}

1) Schonberg W.P., Taylor R.A. :Penetration and Ricochet phenomena in Oblique Hypervelocity Impact, AIAA.J., 27,5(1989)639.

2) Schonberg W.P., Tullos R.J.:Spacecraft Wall Design for Increased Protection Against Penetration by Orbital Debris Impact, ALAA.J.,29, 12 (1991) 2207.

3) Sus S.M., Tzou H.S., Natori M.C.: Parametric Quadraft Programming Method for Dynamic Contact Problems with Friction, ALAA.J., 32, 2(1994) 371.

4) Shirakashi T, Usui E: Effect of Temperature and Strain Rate upon Flow Stress of Metal in Compression, Bull.JSPE,4,4(1970)91. 